\title{
Potential Utilization of Sawdust in Energy, Manufacturing and Agricultural Industry; Waste to Wealth
}

\author{
O. L. Rominiyi ${ }^{*}$, B. A. Adaramola ${ }^{1}$, O. M. Ikumapayi ${ }^{1}$, 0. T. Oginni' ${ }^{2}$, S. A. Akinola ${ }^{3}$ \\ ${ }^{1}$ Department of Mechanical and Mechatronics, Afe Babalola University (ABUAD), Ado-Ekiti, Nigeria \\ ${ }^{2}$ Department of Mechanical Engineering, The Federal University of Technology, Akure, Nigeria \\ ${ }^{3}$ Department of Electrical/Electronics, Ekiti State University, Ado-Ekiti, Nigeria \\ Email: *rominiyiol@abuad.edu.ng
}

How to cite this paper: Rominiyi, O.L., Adaramola, B.A., Ikumapayi, O.M., Oginni, O.T. and Akinola, S.A. (2017) Potential Utilization of Sawdust in Energy, Manufacturing and Agricultural Industry; Waste to Wealth. World Journal of Engineering and Technology, 5, 526-539.

https://doi.org/10.4236/wjet.2017.53045

Received: June 9, 2017

Accepted: August 20, 2017

Published: August 23, 2017

Copyright $\odot 2017$ by authors and Scientific Research Publishing Inc. This work is licensed under the Creative Commons Attribution International License (CC BY 4.0).

http://creativecommons.org/licenses/by/4.0/

\begin{abstract}
Sawdust which is basically considered as a timber-industrial waste that pollutes the environment can become a valuable commodity which is considered in three ways: Manufacturing, Energy and Agricultural utilization. The sawdust is burnt in an updraft gasifier under a limited supply of air to obtain producer gas which is carbon II oxide and hydrogen as main components. The sawdust and other biomass materials are mixed in certain proportions, then bound together and palletized to a small blocks called briquettes. The material was also considered to be composted by mixing it with animal digestion or wood ashes and calcium carbonate to form fertilizers. The sawdust and wood shavings can be used for particle board as well as oil production.
\end{abstract}

\section{Keywords}

Sawdust, Industrial Waste, Producer Gas, Biomass, Briquette, Utilization

\section{Introduction}

Sawdust is a tiny piece of wood that fall as powder from wood as it is cut by a saw [1]. In other words, sawdust is basically a waste of small particles available in saw-milling industries, pulp plant and paper industries as well as wood processing industries particularly, in the southern part of Nigeria in a quite large volume in form of heaps and mostly burnt off resulting in the environmental pollution [2]. Sawdust is generally considered as a timber-industrial waste that pollutes the environment [3] but can become a valuable commodity either as a raw material in manufacturing industries for wood boards, light construction materials such as shelves, notice boards, wall and roof sheeting for mobile houses, as an insulator 
in the refrigerating system and cold conservation of in Energy industries as fuel burned directly or indirectly to produce wood gas, briquette, pellet, etc. Some aspects of the technologies used for the mentioned above shall form part of the discussions in this paper.

Sawdust possesses characteristics similar to wood but due to the fact that it is in particles, some structural properties have been altered. It can however recover this so that it can be used again as wood. Consequently, in utilizing sawdust as a source of energy, its heating value can be compared with that of other fuels. It has a very low thermal conductivity and hence used as insulating material so as to reduce heat losses through conductor. This material is however capable of producing briquettes with density above $100 \mathrm{kgm}^{-3}$. More precisely, the bulk density of sawdust could be as low as $150-200 \mathrm{kgm}^{-3}$ [4]. High pressure and temperature are essential to agglomerate to make a very dense briquette without a binder.

The technological development of sawdust proves its positive use, for instance, it is a requirement for improvement in various forms in different kinds of materials, chemicals such as methanol [5]; as a fuel for instance, it can be burnt directly to obtain heat in three distinct ways [6]:

1) As household fuel energy by burning in special stones for cooking and in fire places for spaces for cooking and in fire places for space heating.

2) For drying and curing, space heating and heating chicken brooders in the agriculture industry.

3) Direct burning in black-smiting, brick making and poultry making in the industrial sector.

Most researchers agreed that all readily recovered waste being generated at present could be absorbed by the industry either for energy supply or for additional raw material for processing chipboards and fine board [7]. Therefore all prime timber is likely to find a ready market for the foreseeable future. For instance, a number of pulp plants in the United States already use their processed wastes to produce other chemicals and beverages quality alcohol.

The exact conditions under which sawdust can be economically viable are hereby highlighted:

1) Energy industries,

2) Manufacturing industries,

3) Agricultural industries.

\subsection{Energy Industries}

The increasing costs, crisis and depletion of energy from convectional sources over past few years have reawakened interest in the development of alternative sources of energy. Many years ago, the world's energy requirements were gases, running water and nuclear energy. Apart from the fact that most of these conventional energy sources are non-renewable, world energy planners have realized that these sources alone would be inadequate to meet the increasing need of the world both now and the future. This led to greater attention being paid to 
the development of wood gas from sawdust which otherwise would be wasted. The technological development of sawdust brought about briquettes which are good alternatives for using wood as fuel [8]. The specific energy content of the wood waste and charcoal are $16,795.96 \mathrm{~kJ} / \mathrm{kg}$, charcoal $18,711.70 \mathrm{~kJ} / \mathrm{kg}$ respectively [9]. It can however be converted to bitumen or heavy oil due to the presence of cellulose in it by processing it with water, sodium carbonate and a gas rich in carbon (ii) oxide (CO) at a temperature of $250^{\circ} \mathrm{C}-400^{\circ} \mathrm{C}$ [5]. Sawdust is beneficial also as insulating materials in the refrigerating system and in cold conservation.

\subsection{Manufacturing Industries}

Application of modern technology in the areas of pulp and paper making, particle board, water board, oriented strand board plywood has resulted in several benefits such as availability of high quality product for making materials such as shelves, wall and roof sheathings, light construction materials and employment opportunities for the populace to mention a few. Several structural wood panels such as mentioned above shall be the focus of this paper under the manufacturing industry.

\subsection{Agricultural Industries}

Sawdust is a useful factor in agricultural industry in making fertilizer called sawdust compost as well as food in chicken brooders. Several million tons of sawdust and other wood residues are produced annually in the Southwest Nigeria. While most of this is burned, an increasing amount is being used for mulches, growers of small fruit, and nurserymen. It is also find an increasing use as litter in barns and feed lots, and as a soil conditioner in general agriculture. Usage has been largely on a trial and error basis, usually with good results. Like other highly carbonaceous organic matter, however, sawdust under certain conditions can cause a deficiency of available nitrogen in soils and thus retard plant growth. Certain woods or bark also contain tannins and other extractives that may have more or less toxic influence on plants and soil microorganisms. To obtain information and fundamental knowledge on these and other problems arising in connection with agricultural uses of wood wastes. It is well known that mulching can increase crop yields, but it is essential that mulches be low-cost, readily available materials. In addition, it is desirable that materials used should not require costly applications of nitrogenous fertilizers during the process of decomposition. Most of our soils are greatly in need of organic matter because the usual crop rotations seldom maintain soil humus at high level as desirable. Wood residues should be utilized for humus maintenance wherever it is economically feasible to do so. Although the emphasis is on sawdust, this material reacts much as do chips, shavings, and bark, except that decomposition is more rapid in the more finely divided material. Sawdust mulches: Improve structure and aeration of heavy soils. Increase water absorption and penetration. Conserve moisture through weed control and reduced evaporation. 


\subsection{Environmental Concerns}

Technological advancement is an important desirable and necessary ingredient of economic and social growth but the environmental consequences can be unpleasant. For example burning sawdust in an open space causes atmospheric pollution landing leading to the problem of acidic rain and the emission of carbon (iv) oxide which is of concern as greenhouse gas [8]. Sawdust seriously affects the soil and water, being a very dangerous threat to the environment. It has three major negative effects on the soil, these include: reduction of the hydrogen content of the soil when used as mulch and reduces soil phosphorous when incorporated. Soil acidity increases and therefore unsuitable for crop germination unless it is composted not good to be used as a fertilizer. Sawdust pollutes the soil with phenol compound. All together these effects reduce the soil productivity [3].

Sawdust reuse is promoted by waste legislation. There is no specific legislation regarding sawdust but there is legislation for wastes in general. As a by-product of timber industry, sawdust is considered by the environmental authorities as a recyclable waste.

\subsection{Sawdust Technology}

\subsubsection{Sawdust Briquetting}

Sawdust and other biomass materials such as palm kernel shell, rice bran, alfalfa straw, olive pits, wheat straw, rice husks, walnut shells, sunflower straw, soybean stalks. Maize cabs, maize stalk etc. are mixed in certain proportions and then bond together with some binding materials. There are various types of binding agents; these include starch, tar, pitch, thermoplastic resin. The use of thermoplastic resin as binding agent is called "Franja" However the addition of binding agent increases the energy content of the material. It is claimed from $800 \mathrm{Btu} / \mathrm{lb}$ for raw wood to at least $1800 \mathrm{Btu} / \mathrm{lb}$ for pellets. These pellets burn at higher temperatures than untreated wood; resulting in more complete burning and less ash residual [5]. Subsequently, the mixtures of sawdust, biomass materials and the binding agents are then molded into small block cubes and cured (by drying out the water content in a drying oven). These cubes are called the briquettes which can then be burned in a special stove for cooking.

\subsubsection{Briquette Techniques}

A screw press was used for destruction of the cell walls to generate heat and a high pressure which is the prerequisite for briquetting of sawdust consequent of the force needed to overcome the natural springiness of these materials (i.e., sawdust, biomass and the binding agents).

\subsubsection{Densification Process of Briquetting}

The process whereby there is a considerable reduction in the volume of the loose sawdust and its aggregates by the application of compressive stress and thereafter leading to its agglomeration so that the product remains in the compressed state is referred to as densification [10]. If the material is compacted with low to 
moderate pressure $(0.2-5 \mathrm{MPa})$; thus reducing the space between particles. As the pressure is increased there will be a stage when the cellulose cell wall of the constituent will collapse [4]. After the densification the material remains as solid until it serves its function well as a fuel. The densification also reduce the moisture content, increase the bulk density, increase the calorific value of the fuel and as well as improving the handling and transporting characteristics. The handling characteristics depend on the following properties:

1) Density,

2) Resistance to humidity,

3) Resistance to mechanical action.

\section{Advantages of Sawdust Briquettes:}

1) Combustion device: It can be combusted more efficiently when briquette then unprocessed sawdust or wood.

2) Briquette is easily fed into the plant unlike the loose sawdust which may be blown out of the combustion zone and may not completely burn.

3) Sawdust briquettes emit little or no smoke when burnt and also burns with high flame.

\subsubsection{Oxygen Gasification of Sawdust}

Gasification of sawdust is the process by which sawdust is burnt with limited supply of air or oxygen. Sawdust gas is composed of carbon (ii) oxide, carbon (iv) oxide, hydrogen and methane. The liquid and the gas are combustible and are potential fuel or fuel feedstock except carbon (iv) oxide. The typical composition from gasification in air, omitting water vapour is as shown in the Table 1 below.

There are some variations, in general the composition of the gas largely independent of the composition of the feedstock because the end product is a mixture of simple gases. In some cases, if there is significant sulphur content in the feedstock hydrogen sulphide may be generated. This can be easily removed by passing the gas through water.

Furthermore, if the air supply is replaced by pure oxygen as it is in the proxy process, the nitrogen content is eliminated and the energy density can be as high

Table 1. Typical composition from gasification of sawdust in air.

\begin{tabular}{cc}
\hline Compounds & Percentage by volume (\%) \\
\hline Hydrogen $\left(\mathrm{H}_{2}\right)$ & 20 \\
Carbon (ii) oxide $(\mathrm{CO})$ & 25 \\
Carbon(iv) oxide $\left(\mathrm{CO}_{2}\right)$ & 10 \\
Methane $\left(\mathrm{CH}_{4}\right)$ & 3 \\
Higher hydrocarbon & 1 \\
Nitrogen & 40 \\
Others & 1 \\
Total & 100 \\
\hline
\end{tabular}

Source: [5]. 
as $9 \mathrm{MJ} / \mathrm{m}^{3}$. Another route to produce the higher BTU gas is by hydro gasification where hydrogen is added to react with the carbon (ii) oxide to give hydrocarbons.

$$
\mathrm{CO}+2 \mathrm{H}_{2} \rightarrow \mathrm{CH}_{4}+\mathrm{H}_{2} \mathrm{O}
$$

\subsubsection{Production of Oil from Sawdust}

The fact that sawdust consists of predominantly carbohydrates (cellulose and hemicellulose), the technology of hydrogenation and carbon (ii) oxide is readily adaptable to converting sawdust to oil. The conversion of cellulose to liquid material requires high pressure hydrogenation and to a bitumen-like material, this requires treatment with caustic at elevated temperatures and pressures.

This process involved heating the feedstock (sawdust), water and catalyst in an autoclave in the presence of carbon(ii) oxide at a desire pressure and to an operating temperature of about $250^{\circ} \mathrm{C}-400^{\circ} \mathrm{C}$ [11]. Water is needed because it supplies the hydrogen for the reaction and also for the hydrolysis of the highmolecular weight carbohydrate present. It also acts as a solvent and vehicle for the reaction. It decreases the extent of polymerization of some of the highly reactive water soluble intermediates.

However, the disadvantages of water in the system are as follows:

1) Using steam at high partial pressure raises the operating pressure to the levels where capital cost tends to be high.

2) The operating costs depend largely on the sum of the heat required to bring water to the operating temperature and pressure.

The separation of the oil and water phases during the product recovery step is sometimes encountered by emulsions. At a temperature of about $250^{\circ} \mathrm{C}-400^{\circ} \mathrm{C}$, the reaction can be flushed from the autoclaves with solvent and the product oil extracted in a soxhlet unit [5].

The extraction can be done using acetone or benzene depending on the temperature at which the reaction occurs. The solvent can then be separated by a rotary evaporated heater in a hot water bath.

\subsection{Sawdust in Manufacturing Industry}

\subsubsection{Composite Structural Panels}

All wood-based structural panels are composite materials. There are a lot of wood panels that can be made from sawdust, these include: Particle board, Oriented strand board, water board, plywood, etc., the strength of which depends on the grain size of the sawdust used.

\subsubsection{Fabrication of Particle Board}

Wood dust in the form of flakes, shavings, chips fibres mixed with resin and other binding agents. This mixture is laid down in a mat which is hot-pressed to increase the density of the mat and to cure the adhesive. The sawdust particles may be oriented to some degree to provide some directionally of strength properties along and across the panels. Particles may be laid down in orthogonal layers similar to plywood veneer. Different types of particles may be used in the 
same panel to improve surface properties and create a more layered particle product [7].

\subsubsection{Hot-Pressing of Particle Board}

In order to overcome the problem associated with spring back and stabilization of the material hot pressing of the sawdust can be carried out for consolidating the particle board to the required thickness and density. It has a direct effect on the product quality and the production efficiency. The function of hot-pressing is to consolidate the material to a desirable panel density and thickness. Modern plants use single-opening or continuous presses for adhesive and furnish to be bonded together to overcome the spring back and heat stabilize the panel for the targeted thickness and density [12]. Production of better panel thickness, controlled density profiles and lower losses in sanding and trimming are assured than for multi opening presses [13].

\subsubsection{Factors Influencing Hot-Pressing}

1) The temperature of the press,

2) The press closing speed,

3) The moisture of the mat and its distribution,

4) The press pressure,

5) The time of pressing,

6) The profile of the thickness [14].

\section{Design Methodology}

\subsection{Typical Machines for Sawdust Utilization}

The aim of this design is to provide a model for the following:

1) A reactor and a storage unit for the production of producer gas during oxygen gasification of sawdust.

2) A manual pressing machine for the production of a particle board of $500 \mathrm{~mm}$ by $600 \mathrm{~mm}$ board and sawdust briquette.

\section{Design Considerations for the}

\section{Reactor}

1) Material Selections and their adequacy for the purpose.

2) Dimensions of the components and unit.

\section{Storage Tank}

1) Volume of gas to be stored.

2) Pressure generated in the storage tank.

3) Dimension of the components and unit.

4) Materials of construction and their adequacy for the purpose.

\section{Pressing Machine}

1) Materials of construction and their adequacy for the purpose.

2) Torque on the screw to be used.

3) Dimensions of the components and unit.

In the designing of unit, efforts were made to use simple manufacturing and engineering techniques to produce units which will serve as a model and which 
is relatively cheap and easily available.

\subsection{The Reactor for Oxygen Gasification of Sawdust}

\subsubsection{Dimension of the Unit}

The dimension of the reactor unit is based on a portable unit that will compose 2 $\mathrm{kg}$ of sawdust biomass at each feeding rate. The specific value of heat content cannot be ascertained. But assertion can be made during the oxygen gasification of wood. The range of the calorific value of both pyrolysis gas and oxygen gasification obtained tends to $11 \mathrm{MJ} / \mathrm{m}^{3}-19 \mathrm{MJ} / \mathrm{m}^{3}$ wood [5].

$2 \mathrm{~kg}$ of sawdust will produce $\frac{2 \times 19}{200}=0.19 \mathrm{MJ} / \mathrm{kg}$.

The density of sawdust which varies from species to species, moisture content is approximately $=750 \mathrm{~kg} / \mathrm{m}^{3}[15]$.

$$
\begin{gathered}
\text { Density }=\frac{\text { Mass }}{\text { Volume }} \\
\text { Volume }=\frac{\text { Mass }}{\text { Density }} \\
\text { Volume }=\frac{2}{750}=0.0027 \mathrm{~m}^{3}=2.7 \times 10^{-3} \mathrm{~m}^{3}
\end{gathered}
$$

This is the volume that $2 \mathrm{~kg}$ mass of sawdust will occupy.

The volume of the producer gas that can be produced during oxygen gasification of sawdust is the addition of the two principal constituents: Carbon (ii) oxide (CO) and hydrogen $\left(\mathrm{H}_{2}\right)$ by percentage of the total volume of gas produced per feeding rate of $2 \mathrm{~kg}$ of sawdust. A specific value cannot be ascertained due to the following conditions:

1) The moisture content.

2) The properties of each wood from which sawdust is being produced.

3) Climatic region under which the tree is grown.

The height and the circumference of the reactor can be calculated using the following assumption:

The diameter to be $0.15 \mathrm{~m}$, therefore, the height of the combustion chamber which is expected to be $\frac{1}{4}$ of the whole reactor that will gasify the sawdust could be calculated as thus.

$$
\begin{aligned}
& \text { Volume of cylinder }=\pi r^{2} h \\
& \begin{aligned}
\text { Volume }=2.7 \times 10^{-3} \mathrm{~m}^{3} \\
r=0.075 \mathrm{~m} \\
h=\frac{2.7 \times 10^{-3}}{\pi \times 0.075} \\
h=0.153 \mathrm{~m}
\end{aligned}
\end{aligned}
$$

The reactor chamber is expected to have a minimum height of $4 \times 0.153=0.61 \mathrm{~m}$

The circumference of the cylinder $=2 \pi r=2 \times 3.142 \times 0.075=0.47 \mathrm{~m}$ 
Therefore, the height and the circumference of the grate that will conveniently gasify the sawdust are $610 \mathrm{~mm}$ and $470 \mathrm{~mm}$ respectively having equal distance between the four major components namely: heating unit, combustion chamber, Gas outlet and feeding unit. The outlet unit where hose can be tightly fixed is assumed to have a diameter of $20 \mathrm{~mm}$ and about $60 \mathrm{~mm}$ long.

\subsubsection{The Storage Unit}

The storage method to be used is the low pressure storage mild steel tank under a pressure slightly higher than the atmospheric pressure.

\subsubsection{Materials Selection}

The materials for construction are a mild steel of $3 \mathrm{~mm}$ thickness gauge 14 SWG (Standard Wire Gauge) which is readily available and relatively cheap.

\subsubsection{Dimensions of the Storage Tanks}

The dimension of the tank is based on the following:

The volume of gas to be stored.

1) The gas production rate from the reactor chamber.

The height " $H$ " of $200 \mathrm{~mm}$ and diameter " $D$ " of $100 \mathrm{~mm}$ are used for the storage tank

Circumference of the storage tank $=\pi D=3.142 \times 100=314.2 \mathrm{~mm}$

$$
\text { Volume of the storage unit }=\frac{\pi D^{2} H}{4}
$$

$$
\text { Volume of the storage unit }=\frac{3.142 \times 100^{2} \times 200}{4}=0.00157 \mathrm{~m}^{3}
$$

\subsubsection{Generated Pressure " $P$ " in the Storage Tank}

$$
P=P_{a}+\rho g h
$$

where:

$P_{a}$ is the atmospheric pressure $\left(\mathrm{N} / \mathrm{m}^{2}\right)$

$\rho$ is the density of air $\left(\mathrm{kg} / \mathrm{m}^{3}\right)$

$g$ is acceleration due to gravity $\left(\mathrm{m} / \mathrm{s}^{2}\right)$

$h$ is height of the tank (m)

$P$ is the permissible pressure $\left(\mathrm{kN} / \mathrm{m}^{2}\right)$

$$
\begin{gathered}
P=1.01325 \times 10^{5}+1.3 \times 9.82 \times 0.2 \\
P=101328 \mathrm{~N} / \mathrm{m}^{2} \\
P=101.328 \mathrm{kN} / \mathrm{m}^{2}
\end{gathered}
$$

From the Table 2 [16] above the Atmospheric $\mathrm{N}_{2} / \mathrm{O}_{2 \text {,ratio }}=\frac{78.084}{20.948}=3.73$

Molar mass of air $=($ molar mass of Nitrogen $\times$ volume of nitrogen $)$

$$
\begin{aligned}
& +(\text { molar mass of Oxygen } \times \text { volume of oxygen }) \\
= & (28.150 \times 0.790)+(31.9988 \times 0.210)
\end{aligned}
$$

$$
=28.960 \mathrm{~g} / \mathrm{mol}
$$


Table 2. Composition of dry air by volume.

\begin{tabular}{cc}
\hline Constituents & \% by Volume \\
\hline Nitrogen $\left(\mathrm{N}_{2}\right)$ & 78.084 \\
Oxygen $\left(\mathrm{O}_{2}\right)$ & 20.948 \\
Argon $(\mathrm{Ar})$ & 0.934 \\
Carbon (iv) oxide $\left(\mathrm{CO}_{2}\right)$ & 0.031 \\
Hydrogen and other gases & 0.03 \\
\hline
\end{tabular}

Source: [16].

\subsubsection{The Stress of the Cylindrical Vessel " $\delta$ "}

$$
\delta_{w}=\frac{P d}{2 t}[17]
$$

where:

$\delta_{w}$ is the stress of the cylindrical vessel (Design Pressure)

$P$, is the permissible pressure

$t$, is the thickness of the material

$d$, is the diameter of the storage tank $=100 \mathrm{~mm}$

Factor of safety $=3$

$$
\delta_{w}=\frac{\delta_{y}}{\text { Factor of safety }}
$$

where;

$\delta_{w}$ is the working stress

Yield Stress of the mild steel $=200 \mathrm{~N} / \mathrm{mm}^{2}$

$$
\begin{gathered}
\delta_{w}=\frac{200}{3}=66.7 \mathrm{~N} / \mathrm{mm}^{2} \\
t=\frac{1.01327 \times 10^{-4}}{2 \times 66.7} \times 0.1 \\
t=7.6 \times 10^{-8} \mathrm{~mm}
\end{gathered}
$$

Therefore a mild steel of $2 \mathrm{~mm}$ thickness will be adequate to store the gas under a pressure of $101.327 \mathrm{kN} / \mathrm{m}^{2}$.

\subsubsection{The Pressing Machine}

A mild steel of $3 \mathrm{~mm}$ thickness, gauge 18 SWG, (Standard Wire Gauge), a steel rod of thickness $10 \mathrm{~mm}$ and a screw and nut that is readily available and relatively cheap are used.

The dimensions of the pressing machine and the mould that will produce a sizeable particle board and briquette are based on the following:

1) The volume of the mould that will produce the particle board of $500 \mathrm{~mm} \times$ $600 \mathrm{~mm} \times 20 \mathrm{~mm}$ in dimension.

2) The internal bonding stress that will be generated inside the sawdust.

3) The work done by the screw on the biomass.

$$
V s=l b H_{b}
$$

where: 
$V s$ is the Volume and the mass of sawdust and binder

$l$ is length of the particle board

$b$ is the breadth of the particle board

$H_{b}$ is the thickness of the particle board

$$
\begin{gathered}
V s=500 \times 600 \times 20\left(\mathrm{~mm}^{3}\right) \\
V s=6.0 \times 10^{6} \mathrm{~mm}^{3} \\
V s=6.0 \times 10^{-3} \mathrm{~m}^{3}
\end{gathered}
$$

Density of sawdust is taken to be $750 \mathrm{~kg} / \mathrm{m}^{3}$

$$
\text { Mass of sawdust and binder }=\text { Density } \times \text { Volume }
$$

$$
\text { Mass of sawdust and binder }=750 \times 6.0 \times 10^{-3}=4.5 \mathrm{~kg}
$$

\subsubsection{The Internal Bonding Pressure " $P_{i}$ "}

$P_{i}=$ Density of sawdust $\times$ Acceleration due to gravity $\times$ thickness of the board

$$
\begin{gathered}
P_{i}=750 \times 9.82 \times 0.02 \\
P_{i}=147.30 \mathrm{~N} / \mathrm{m}^{2}
\end{gathered}
$$

\subsubsection{The Torque of the Screw Used}

$$
T=\operatorname{Cot}_{b} f_{i}
$$

where: $T$ is the Torque of the screw

Co is the Torque coefficient $0.2 \pm 0.06$

$t_{b}$ is the thickness of the bolt in (mm)

$f_{i}$, is the initial tightening force in the bolt $(\mathrm{N})$

$$
f_{i}=0.9 t_{a} \delta_{p}
$$

where: $t_{a}$ is the stress area

$\delta_{p}$ is the proof stress

The proof strenght for steel screw thread $=350 \mathrm{MPa}$

The thickness of the bolt is $10 \mathrm{~mm}$

The stress area $t_{a} \quad\left(\mathrm{~mm}^{2}\right)=58 \mathrm{~mm}^{2}$

The tightening tension " $f_{i}$ " $=0.9 \times 58 \times 10^{-6} \times 350 \times 10^{6}$

$$
f_{i}=18270 \mathrm{~N}
$$

Then the tightening torque " $T$ " $=0.2 \times 10 \times 10^{-3} \times 18270$

$$
T=36.54 \mathrm{~N} \cdot \mathrm{m}
$$

The work done on the biomass to keep the keep the particle board in a thickness of $20 \mathrm{~mm}$ depends on the force on the screw and the screw distance to maintain that thickness.

$$
\begin{gathered}
W=f d \\
W=18270 \times 0.02=365.40 \mathrm{~J}
\end{gathered}
$$

\subsection{Contact Stress}

When surface are placed in contact they touch at one or few discrete points. 
When the surface of the wood (the top materials) is loaded, the contacts flatten elastically and the contact area grows until failure of some sort occurs [19]:

1) Failure by crushing caused by compressive stress " $\delta c$ "

$$
\delta c=\frac{3 f}{2 \pi a^{2}}
$$

where, $f$ is the tightening force of the screw $=18,270 \mathrm{~N}$

$a$ is the radius of contact $=50 \mathrm{~mm}$ ( i.e. $\frac{100}{2}$ )

$$
\delta c=\frac{3 \times 18270}{2 \times \pi \times 0.05}
$$

2) Tensile fracture caused by the tensile stress " $\delta t$ "

$$
\delta t=\frac{f}{6 \pi a^{2}}=\frac{18750}{6 \times \pi \times 0.05^{2}}=387701.4 \mathrm{~N} / \mathrm{m}^{2}
$$

3) The yielding stress caused by the shear stress

$$
\delta s=\frac{f}{2 \pi a^{2}}=\frac{18270}{2 \times \pi \times 0.05^{2}}=1163104.324 \mathrm{~N} / \mathrm{m}^{2}
$$

\section{Sawdust Utilization for Feed Meal, Compost and Mushrooms Production}

Uncontaminated sawdust and wood shavings are useful for soaking up excess moisture in wet compost heaps and as a dry "brown", are useful for balancing out "green"-heavy compost heaps that might otherwise go sludgy. Stir them into the existing compost so they get damp and to also stop them either forming a dense layer on top (which might reduce the air flow in the heap) or blowing around the garden. (If the heap has a tendency to be on the dry side, extra moisture is added when adding sawdust otherwise it might dry up all together). Sawdust or wood shavings used as animal bedding can be added as long as the animal is vegetarian-for example, rabbits or most chickens droppings feathers or fur can be added to the heap along with the sawdust-it will all compost down nicely together. Ruminant animals can also utilize cellulosic materials as food because of a valuable symbiotic relationship with microorganisms present in the rumen section of their digestive tract.

Cellulose pulps and wood waste have been fed as maintenance rations to cattle and horses during times of great national emergencies. Another potential agricultural uses of wood waste is in the rations for flattering cattle. Feeding trials were conducted with and sheep using based all concentrate formula with and without sawdust and oyster shell.

The addition of inexpensive source of cellulose to a purified experimental chick ration resulted to a significant increase in growth. Spruce wood flour fed to chicks at a level of 20.2 percent of the diet in a practical-type ration without detrimental effects and brought about slight increases of growth at 28 weeks of age when compared with the control group. 


\section{Conclusions}

Sawdust that ordinarily constitutes a menace in sawmills is a good source of fuel, biogas, animal feed meal, organic manure, weed killer and particle board and briquettes. The flame-purified gas is found useful to power internal combustion engines.

Also, the particle boards and plywood products are prefer to other materials like asbestos in roof and wall sheathings for safety and health reasons. Finally, composting sawdust with livestock droppings can be of a great prospect for soil conditioning.

\section{Recommendations}

Government should create enabling environment for the manufacturing of pressing machine and briquetting machines locally. If briquetting machines as well as pressing machines are developed here in Nigeria, for local consumption and export, we would have gained more money in foreign exchange.

Indiscriminate burning of sawdust directly should be discouraged through government supported seminars and workshop within the country.

Sawdust briquette should be used as an alternative fuel in place of kerosene and firewood.

\section{References}

[1] Hornby, A.S. (1998) Advance Learner Dictionary. Special Priced Edition, Oxford University Press, Oxford.

[2] Adegoke, C.O. and Mohammed, T.I. (2002) Investigation of Sawdust Briquettes as High Grade Fuels. The West Indian Journal of Engineering, Faculty of Engineering, University of West Indies.

[3] Alexandru, R.S. (2002) Putting Sawdust to Work in Romanian. Planet's Voice Article, Planet Voice Org.

[4] FAO (1989) The Briquetting of Agricultural Wastes for Fuel. FAO Production Environmental Energy Paper II.

[5] Goodger, E.M. (1980) Alternative Fuel Chemical Energy Resources. Macmillan, London Bagsing Stock.

[6] Adegoke, C.O. (2003) Available Alternative Energy Source for Domestic Use: A Case Study of Solar Cookers, Dryers and Sawdust Briquettes. Paper Work.

[7] Thomas, E.M. (1975) Wood Engineering and Construction Hand Book. Southern Illinois University Press.

[8] Adegoke, C.O. (2002) Energy a Veritable Tool for Sustainable Environment. A Lecture Delivered at a Conference in Federal University of Technology, Akure.

[9] Rominiyi, O.L. (2015) Evaluation of Energy Content of the Municipal Solid Waste of Ado-Ekiti, Metropolis, M. Eng Thesis, Department of Mechanical Engineering, The Federal University of Technology, Akure.

[10] Vis Viva Renewable Energy Plot 38-b, RD\&E Cooperative Housing Society, Kalas, Pune, Maharashtraph. http://www.vvenergy.com

[11] El-Gayar, M.S. (1997) Shellsol as a Processing Liquid in Biomass Liquefaction. Energy Sources Part a Recovery Utilization and Environmental Effects. 
https://doi.org/10.1080/00908319708908881

[12] Okebola, F.O. (1985) Modern Wood-Work Technology for Polytechnics and Technical Colleges. Ilesanmi Press Limited.

[13] Moslem, A.A. (1974) Particle Board. Vol. 1, Materials, Southern Illinois University Press, Carbondale.

[14] Chrisis (2002) Applying Research in Forestry. Department of Horticulture, University of Missouri. http://mdc.mo.gov.www.google.com

[15] Ashby (1999) Wood Density and Modulus of Elasticity.

[16] ASHREA (1977) Handbook of Fundamentals. American Society of Heating Refrigerating and Air Conditioning Engineers, Inc.

[17] Ryder, G.H. (1982) Strength of Material. 3rd Edition, Macmillan Press, Hong Kong.

[18] Fogiel, M. (1989) The Machine Design Problem Solver Research and Education Association.

[19] Ashby, M. (2000) Design Formulae for Simple Structure. Metal Foams.

Submit or recommend next manuscript to SCIRP and we will provide best service for you:

Accepting pre-submission inquiries through Email, Facebook, LinkedIn, Twitter, etc. A wide selection of journals (inclusive of 9 subjects, more than 200 journals) Providing 24-hour high-quality service

User-friendly online submission system

Fair and swift peer-review system

Efficient typesetting and proofreading procedure

Display of the result of downloads and visits, as well as the number of cited articles Maximum dissemination of your research work

Submit your manuscript at: http://papersubmission.scirp.org/

Or contact wjet@scirp.org 